\title{
"Refugiados Ambientais" e a Lacuna Jurídica no Direito Internacional Público
}

\author{
Patrícia Fernanda Scalco \\ Mestre em Direito e Relações Internacionais pela Uni- \\ versidade Federal de Santa Catarina (UFSC). Bacharel \\ em Direito pelo Complexo de Ensino Superior de Santa \\ Catarina. Atualmente é advogada e membro do Grupo de \\ Pesquisa em Direito Internacional - lus Gentium UFSC/ \\ CNPq. patrícia.f.scalco@gmail.com.
}

\section{Resumo:}

0 presente artigo possui como tema o problema dos "refugiados ambientais" e objetiva debater acerca da atual situação jurídica dos denominados "refugiados ambientais" em virtude da lacuna jurídica existente com relação ao enquadramento destes no âmbito do direito internacional público. Após a análise do problema, será possível extrair que o tema não encontra tutela internacional em razão de problemas enfrentados, primeiramente, com relação a sua nomenclatura, bem como a ausência de enquadramento conceitual de refugiados conforme prevê a Convenção de Refugiados de 1951, incidindo, assim, maior gravidade à situação fática, uma vez que o número de migrantes em decorrência dos desastres ambientais deve aumentar de maneira alarmante.

Palavras-chave: Risco ambiental. Mudanças climáticas. "Refugiados ambientais". Direito Internacional Público.

\section{"ENVIRONMENTAL REFUGEES" AND THE LOOPHOLE IN THE FRAMEWORK OF INTERNATIONAL PUBLIC LAW}

\begin{abstract}
:
This article examines the problem of the so-called "environmental refugees" intending to debate about their current legal situation regarding the loophole existing in the framework of international public law. After analyzing the problem, it would be possible to establish that the issue studied does not find
\end{abstract}


international legal protection mainly due to the absence of definition and recognition of this new category of refugees in the 1951 Refugee Convention. This situation has a serious impact on the factual background every time that the number of migrants caused by natural disasters increases alarmingly.

Keywords: Environmental risk. Climate change. "Environmental refugees". International Public law.

\section{Sumário}

1 Introdução. 2 As Alterações Climáticas e o Aumento dos "Refugiados Ambientais". 3 0s Debates Sobre 0 Reconhecimento de Uma Nova Categoria de Refugiados. 4 Possibilidades Para Suprir a Lacuna Jurídica. 5 Considerações Finais. 6 Referências. 


\section{INTRODUÇÃO}

Os impactos ambientais crescentes causam o aumento da fome e da miséria, majoram a ausência de segurança individual e coletiva, comprometem a vida, sobrevivência e a dignidade das pessoas que se encontram em situações em que foram expulsas do local de origem, seja de maneira temporária ou definitiva, e de tudo que possuíam para a sua sobrevivência em decorrência de furacões, enchentes, secas rigorosas, desertificação dos solos, tsunamis, erosão do solo, acidentes industriais dentre outros desastres ambientais que, influenciados ou não pelo homem, deixam à deriva milhares de pessoas que, na tentativa de se restabelecer, mudam-se para outros Estados, cidades, países e, infelizmente, sem nenhuma proteção jurídica que os tutele, fazendo surgir, então, os "refugiados ambientais".

Diante do quadro elucidado, o questionamento que surge é: O que são "refugiados ambientais”? Existe solução para o problema?

\section{AS ALTERAÇÕES CLIMÁTICAS E O AUMENTO DOS "REFUGIADOS AMBIENTAIS"}

Nos últimos anos é possível perceber uma grande movimentação de migrantes em todo o globo. Eles buscam, na maioria das vezes, um recomeço na procura por melhores condições de vida como estratégia humana em resposta às alterações climáticas.

A questão principal é que os indivíduos não podem migrar simplesmente por escolha. A legislação nacional e internacional tutela em específico alguns desses movimentos migratórios, destacando-se os refugiados abarcados pelo Estatuto do Refugiado de 1951 e os apátridas, bem como os indivíduos que migram em decorrência de emprego, família, educação. Os demais que tentam cruzar fronteiras internacionais de maneira ilegal, podem ser interditados, deportados e expulsos. 
O problema dos "refugiados ambientais" encontra duas dificuldades: não existe legislação nacional que os tutele quando migram dentro de seu território, e tampouco no âmbito internacional, quando tentam atravessar fronteiras entre Estados.

Entre os maiores desastres ambientais que obrigaram milhares de pessoas a migrar, pode-se citar o Furacão Katrina nos EUA, quando aproximadamente meio milhão tiveram de deixar suas casas deslocando-se, principalmente, para outros Estados; o terremoto no Japão, em março de 2011, que deixou milhares de desaparecidos e causou um inchaço populacional em outras áreas; o Ciclone Nagis, de 2008, com um milhão de desabrigados; em Blangadesh, o aumento do nível do mar fez com que milhares se deslocassem; o terremoto seguido de tsunami na Indonésia, que também atingiu a Somália, onde vilas inteiras foram devastadas, deixando um grande número de mortos, desaparecidos e cerca de 50 mil pessoas buscando novos lugares para se restabelecer.

Outro problema climático ainda mais grave é o que atingiu o Sudão do Sul. Em virtude da desertificação e escassez de recursos naturais, gerou conflitos étnicos, religiosos e uma guerra civil que durou 22 anos e provocou deslocamento de 2,7 milhões de pessoas.

Diante de tal quadro, pode-se afirmar que a situação dos "refugiados ambientais" é uma questão que envolve a paz e a segurança internacional, pois, a exemplo de como ocorreu no Sudão do Sul, as previsões afirmam que os conflitos podem não se restringir apenas dentro das fronteiras nacionais, mas, sim, em âmbito internacional, e o problema se tornar de difícil solução, gerando, consequentemente, uma violação maciça de direitos humanos mínimos, não delimitando classe social ou grupos (Ramos, 2011).

Conforme destacou Érika Ramos (2011), é importante ressaltar que, muitas vezes, a destruição do meio ambiente é utilizada como estratégia para a guerra. As grandes ondas migratórias ocorreram em locais 
com maiores problemas sociais, econômicos e políticos, pois a capacidade de resposta por parte do governo ou entidades é tardia e os conflitos se agravam rapidamente.

Os conflitos no Continente Africano e Oriente Médio com relação aos problemas hídricos são exemplos. A ausência de água potável e as secas agravam a fome e a miséria, principalmente na África (Ramos, 2011).

Em virtude da instabilidade dos incidentes climáticos, os Estados deixaram de tratar o problema de maneira isolada e passaram a ver como um risco para toda a comunidade internacional. Em 2007 a temática foi levada ao Conselho de Segurança da Organização das Nações Unidas para debate sobre como as mudanças climáticas influenciam os litígios já existentes e podem desencadear crises humanitárias (ONU, 2007).

Atualmente, os brasileiros podem acompanhar a situação típica dos conhecidos "refugiados ambientais" pela questão haitiana. Em razão de um terremoto ocorrido em 2010 que devastou a nação, os haitianos, que já se encontravam em uma situação extremamente delicada em virtude da pobreza extrema, desigualdade social e violência generalizada, após o terremoto viram-se sem perspectivas para continuar no país e, como consequência, criou-se uma onda migratória diretamente ligada à catástrofe natural, sendo o Brasil um dos principais países a receber pedidos de refúgios por parte dos haitianos.

\section{OS DEBATES SOBRE O RECONHECIMENTO DE UMA NOVA CATEGORIA DE REFUGIADOS}

Para mais bem elucidar a questão envolvendo os "refugiados ambientais”, cabe destacar alguns conceitos trazidos pelo Direito Internacional Público. Primeiramente o que são migrantes, deslocados internos e refugiados. 
Migrante é todo o indivíduo que se desloca no espaço. Podem ter várias origens, como, por exemplo, os migrantes econômicos que, segundo o Alto Comissariado das Nações Unidas para os Refugiados (Acnur) (Alto..., 2014b),1 “decidem deslocar-se para melhorar as perspectivas para si mesmos e para suas famílias”. Os deslocados internos são:

[...] pessoas que se deslocam dentro de seu próprio país [...] não atravessaram uma fronteira internacional para encontrar segurança, mas permaneceram em seu país natal. Mesmo se fugiram por razões semelhantes às dos refugiados [...] legalmente os deslocados internos permanecem sob a proteção de seu próprio governo, ainda que este governo possa ser a causa da fuga. Como cidadãos, eles mantêm todos os seus direitos e são protegidos pelo direito dos direitos humanos e o direito internacional humanitário. ${ }^{2}$

Já o conceito de refugiado possui legislação específica que é a Convenção dos Refugiados de 1951 e o Protocolo de 1967:

Refugiado é alguém que temendo ser perseguido por motivos de raça, religião, nacionalidade, grupo social ou opiniões políticas, se encontra fora do país de sua nacionalidade e que não pode ou, em virtude desse temor, não quer valer-se da proteção desse país. ${ }^{3}$

Realizando a interpretação do conceito de refugiado, é possível perceber que os denominados "refugiados ambientais" não são abarcados pela legislação vigente, pois a migração do mesmo não ocorre por motivo

${ }^{1}$ Alto Comissariado das Nações Unidas para os Refugiados. Acnur. 2014. Disponível em: $<\mathrm{http}$ ///www.acnur.org/t3/portugues/quem-ajudamos/refugiados $>$. Acesso em: 15 jan. 2014.

${ }^{2}$ Alto Comissariado das Nações Unidas para os Refugiados. Acnur. 2014. Disponível em: $<\mathrm{http}$ ///www.acnur.org/t3/portugues/quem-ajudamos/refugiados $>$. Acesso em: 15 jan. 2014.

${ }^{3}$ Alto Comissariado das Nações Unidas para os Refugiados. Acnur. 2014. Disponível em: $<\mathrm{http}$ //www.acnur.org/t3/portugues/quem-ajudamos/refugiados >. Acesso em: 15 jan. 2014. 
de perseguição racial, étnica, religiosa, política, mas, sim, porque o local onde vivia foi destruído de maneira permanente ou temporária por desastres ambientais.

Existem também as convenções regionais que legislam acerca do Instituto do Refúgio, em que podemos destacar a Declaração de Cartagena, reiterada pela Declaração de São José sobre Refugiados e Pessoas Deslocadas de 1994, do Sistema Interamericano de Proteção aos Direitos Humanos e a Convenção da Organização da Unidade Africana. Tais convenções são conhecidas por sua inovação na busca por uma maior amplitude acerca do Instituto do Refugiado, objetivando maior assistência aos indivíduos que se encontram em situações extremamente complexas e delicadas, necessitando de amparo.

Deste modo, a definição ou o conceito de refugiado recomendável para sua utilização na região é o que, além de conter os elementos da Convenção de 1951 e do Protocolo de 1967, considere também como refugiados as pessoas que tenham fugido dos seus países porque a sua vida, segurança ou liberdade tenham sido ameaçadas pela violência generalizada, a agressão estrangeira, os conflitos internos, a violação maciça dos direitos humanos ou outras circunstâncias que tenham perturbado gravemente a ordem pública. ${ }^{4}$

Efetivamente, no entanto, não existe nenhum instrumento internacional que possua caráter vinculante, de alcance universal e que seja específico sobre esse tema. Pode-se concluir que, talvez, um dos motivos da falta de um instrumento específico seja em decorrência da ausência de consenso sobre o conceito dos "refugiados ambientais".

${ }^{4}$ Alto Comissariado das Nações Unidas para os Refugiados. Acnur. Declaração de Cartagena de 1994: Terceira Conclusão. Disponivel em: <http://www.acnur.org/t3/portugues/recursos/documentos/?tx_danpdocumentdirs_pi $2 \% 5 B m o d e \% 5 \mathrm{D}=1 \& \mathrm{tx}$ _danpdocumentdirs_ pi2\%5Bfclick $\% 5 \mathrm{D}=, 145 \& \mathrm{tx}$ _danpdocumentdirs_pi2\%5Bfolder\%5D=146\&tx_danpdocumentdirs_pi2\%5Bsort $\% 5 \mathrm{D}=$ doctitle,sorting,uid\&tx_danpdocumentdirs_pi2\%5Bpointer\%5D $=0>$. Acesso em: 6 jan. 2014. 
A primeira vez em que se ouviu o conceito sobre o tema foi em 1948, quando eram denominados de "refugiados ecológicos”, mas, oficialmente, o termo "refugiados ambientais" foi utilizado por El-Hinnawi ${ }^{5} \mathrm{em}$ 1985, alertando sobre os impactos ambientais devastadores, poluição e a preocupação sobre emissão do gás carbono. ${ }^{6}$

Durante a década de 80, o tema era tratado somente por especialistas científicos e ambientalistas, no entanto, pela amplitude do problema, em 1990 foi realizado o Painel Intergovernamental sobre Mudanças Climáticas (em inglês, IPCC) (McAdam, 2011). Atualmente, este se transformou em um órgão da ONU responsável por produzir informações acerca das alterações climáticas. ${ }^{7}$ A partir de 2000 em diante, as consequências das alterações climáticas passaram a ser mais evidentes e as consequências se tornaram inevitáveis.

Em 2005, a Sub-Comissão das Nações Unidas para a Promoção e Proteção dos Direitos Humanos aprovou uma resolução sobre "As implicações legais do desaparecimento dos Estados e de outros territórios por razões ambientais, incluindo as implicações para os direitos humanos de seus moradores, com especial referência para os direitos dos povos naturais". 8

${ }^{5}$ Essam El- Hinnawi, professor do Egyptian National Research Centre, Cairo. Trabalhou no Programa sobre Meio Ambiente da Organização das Nações Unidas (Unep, sigla em inglês). É considerado uma referência em assuntos sobre Refugiados Ambientais, tendo escrito vários artigos sobre 0 assunto.

${ }^{6}$ McAdam, Jane. Legal and Protection Policy Research Series: Climate Change Displacement and International Law. Suíça: United Nations High Commissioner For Refugees (unhcr), 2011. 71p. Disponível em: <http://www.unhcr.org/4dff16e99.pdf>. Acesso em: 6 jan. 2014.

${ }^{7}$ Para maiores informações sobre o órgão ver: <http://www.wwf.org.br/natureza_brasileira/ reducao_de_impactos2/clima/painel_intergovernamental_de_mudancas_climaticas/>.

${ }^{8}$ McAdam, Jane. Legal and Protection Policy Research Series: Climate Change Displacement and International Law. Suíça: United Nations High Commissioner For Refugees (unhcr), 2011. 71p. Disponível em: <http://www.unhcr.org/4dff16e99.pdf>. Acesso em: 6 jan. 2014. 
No ano de 2009, a Assembleia Geral das Nações Unidas adotou a resolução “Mudanças Climáticas e suas Seguras Implicações”, e requereu que o Conselho de Segurança fizesse um relatório acerca dos deslocamentos em virtude das mudanças climáticas (McAdam, 2011).

Em razão dos acontecimentos envolvendo os impactos climáticos, os órgãos da Organização das Nações Unidas (ONU) que trabalham com refugiados, direitos humanos e questões humanitárias em conjunto com a literatura, iniciaram longos debates sobre o problema de como tutelar os indivíduos que se encontram em situação de risco.

O cientista ambiental Norman Myers, autor do livro Environmental Exodus: An Emergent Crisis in the Global Arena, publicado em 1995, juntamente com Jennifer Kent, afirmou que "refugiados ambientais":

[...] são pessoas que já não conseguem ter uma vida segura em sua terra natal por causa dos fatores ambientais de âmbito incomum. Esses fatores incluem a seca, a desertificação, os desmatamentos, erosão do solo e outras formas de degradação dos solos; déficit de recursos, tais como a escassez de água, o declínio dos habitats urbanos através da sobrecarga maciça dos sistemas de cidade, problemas emergentes, tais como as mudanças climáticas, especialmente o aquecimento global, e desastres naturais como ciclones, tempestades e inundações, terremotos, com impactos agravados pela má gestão humana. Pode haver fatores adicionais que exacerbam os problemas ambientais e que muitas vezes resultam, em parte, de problemas ambientais: o crescimento populacional, a pobreza generalizada, fome e doença pandêmica. Ainda há outros fatores que incluem as políticas de desenvolvimento deficiente e sistema de governo de marginalizam o povo em sentido econômico, político, social e jurídico. Em certas circunstâncias, um número de fatores pode servir como "gatilhos" imediatos da migração, por exemplo, grandes acidentes industriais e construção de grandes barragens. Desses fatores múltiplos, vários podem operar em conjunto, muitas vezes com impactos agravados. Diante dos problemas ambien- 
tais, pessoas envolvidas sentem que não tem alternativa senão a de buscar o sustento em outro lugar, dentro de seus países ou em outros países, em uma base permanente ou semipermanente. ${ }^{9}$

O que primeiramente deve ser verificado é que o impacto ambiental é o principal fator que ocasiona a migração de grupos de indivíduos para locais dentro das fronteiras nacionais ou internacionais, podendo ser temporárias ou permanentes.

Em virtude da ausência de uma nomenclatura adequada, os "refugiados ambientais" são denominados por alguns doutrinadores de "ecorrefugiados”, "refugiados climáticos”, “deslocados ambientais”, "migrantes ambientais", dentre outros, gerando correntes com vieses opostos e inúmeras discussões no âmbito do Direito Internacional, considerando que nenhum dos termos adotados encontra tutela no âmbito internacional.

Existe a corrente que nega totalmente a existência do termo "refugiados ambientais" (teoria minimalista), uma vez que não está enquadrado na definição trazida pela Convenção dos Refugiados de 1951. Já a corrente que

\footnotetext{
${ }^{9}$ Tradução livre. No original: [...] Environmental refugees are persons who can no longer gain a secure livelihood in their traditional homelands because of what are primarily environmental factors of unusual scope. These factors include drought, desertification, deforestations, soil erosion and other forms of land degradation; resource deficits such as water shortages; decline of urban habitats through massive over-loading of city systems; emergent problems such as climate change, especially global warming; and natural disasters such as cyclones, storm surges and floods, also earthquakes, with impacts aggravated by human mismanagement. There can be additional factors that exacerbate environmental problems and that often derive in part from environmental problems: population growth, widespread poverty, famine and pandemic disease. Still further factors include deficient development policies and government systems that "marginalize" people in senses economic, political, social and legal. In certain circumstances, a number of factors can serve as "immediate triggers" of migration, e.g. major industrial accidents and construction of outsize dams. Of these manifold factors, several can operate in combination, often with compounded impacts. In face of environmental problems, people concerned feel they have no alternative but to seek sustenance elsewhere, either within their countries or in other countries, and whether on a semi-permanent or permanent basis. Myers, Norman; Kent, Jennifer. Enviromental Exodus: An Emergent Crisisin the Global Arena. Washington: Project Of The Climate Institute, 1995. p. 18. Disponível em: <http://www.climate.org/PDF/ Environmental Exodus.pdf>. Acesso em: 5 dez. 2013.
} 
podemos definir como "intermediária” restringe o uso do termo "refugiados ambientais" a situações específicas, como, por exemplo, a passagem de um tsunami, por ter ocorrido de forma repentina. Já a terceira corrente, que é mais conhecida internacionalmente, classifica os "refugiados ambientais" como gênero e as espécies dividem-se em: refugiados devido a catástrofes, expropriações ou deterioração do meio ambiente (Ramos, 2011).

Outra questão debatida entre os cientistas e que deve ser considerada sobre o conceito de "refugiados ambientais", refere-se à questão de que ciclones, tempestades, tsunamis são condições meteorológicas extremas e não eventos climáticos. Consequentemente, o fator inerente aos refugiados deve estar ligado à natureza do dano, não a sua fonte (McAdam, 2011).

O envolvimento do Acnur (Alto..., 2014) sobre o problema dos refugiados ambientais teve início nos anos 90. Conforme relatório de 1993 sobre refugiados:

[...] Milhões de pessoas foram forçadas a deixar suas casas por causa que a terra em que vivem tornou-se inabitável ou já não é capaz de apoiá-los. Em alguns casos, a causa é um desastre natural, em outros, a catástrofe é causada por seres humanos. A interrupção do habitat pode ser súbito, como em Chernobyl ou no Monte Pinatubo, ou gradual, como a propagação de um deserto ou a retirada de uma floresta. [... $]^{10}$

Nos anos que se seguiram, no entanto, os debates acerca do tema por parte do órgão sofreram um grande declínio e o problema dos refugiados ambientais passou a ser discutido principalmente por estudiosos sobre migração (Terminski, 2011).

\footnotetext{
${ }^{10}$ Tradução livre. No original: [...] Millions of people have been forced to leave their homes because the land of which they live has become uninhabitable or is no longer able to support them. In some cases the cause is a natural disaster; in others, the catastrophe is caused by humans. The disruption to the habitat may be sudden, as at Chernobyl or Mount Pinatubo or as gradual as the spread of a desert or the retreat of a forest [...]. Disponivel em: <http://www.cedem.ulg.ac.be/wp-content/uploads/2012/09/Environmentally-Induced-isplacement-Terminski-1.pdf $>$. Acesso em: 7 jan. 2014.
} 


\section{POSSIBILIDADES PARA SUPRIR A LACUNA JURÍDICA}

As estatísticas para o ano de 2020 preveem que o número de refugiados em decorrência de alterações climáticas será de 20 milhões (ONU, 2014), um número extremamente preocupante, principalmente porque, mesmo os refugiados que estão protegidos pela Convenção de 1951, encontram inúmeros desafios para continuar sobrevivendo. O que será desses 20 milhões de indivíduos que se encontram desprotegidos de tutela específica?

Cabe ressaltar que, por mais que no âmbito do Direito Internacional Público não existe nenhuma convenção específica, os "refugiados ambientais” possuem a proteção de direitos humanos mínimos, ou seja, o direito à vida e à dignidade. Tal proteção é extremamente frágil, no entanto é um standard mínimo conferido pelos instrumentos internacionais de proteção que os indivíduos possuem para se resguardar.

A importância do reconhecimento dessa categoria como refugiados é em razão das consequências que o status concede ao indivíduo. A Convenção para Refugiados de 1951 ainda hoje é o principal ponto de referência nessa matéria. Mesmo que não tenha acompanhado as mudanças, prevê que os refugiados têm direito à assistência material e jurídica, à proibição de ser forçado a retornar ao Estado de origem, conhecido como o princípio do non refoulement (não devolução), direito a uma vida segura (repatriação voluntária), à obrigação de acolhida do país em que o indivíduo optou por refúgio (integração local) ou um país terceiro (reassentamento), dentre outras obrigações convencionadas que os Estados possuem (Ramos, 2011).

Contudo, é importante salientar que os principais instrumentos internacionais de proteção a refugiados de alcance universal permanecem restritivos no tocante aos critérios para a concessão dos status de refu- 
giado, havendo uma forte tendência para que assim permaneça, reflexo direto do enrijecimento das políticas de imigração, especialmente no caso da Europa e dos Estados Unidos (Ramos, 2011, p. 104).

Como assinalado na Convenção de 1951, para obter o status de refugiado é necessário o elemento de perseguição como fundamento base. Pela legislação vigente o perseguidor seria formado por elementos provocados pelo homem. Para um possível enquadramento dos "refugiados ambientais", no entanto, a estudiosa Liliana Jubilut afirmou que o elemento perseguidor pode ser caracterizado pela degradação ambiental.

Diferentemente das vítimas de perseguição, as pessoas que se deslocam em razão de um desastre ambiental podem, em geral, valer-se da ajuda e do suporte do próprio governo, mesmo que tal suporte seja limitado. Isso não se confunde com a situação em que o agente perseguidor utiliza a degradação ambiental como meio de perseguição. Neste caso, a razão da perseguição pode ser uma das previstas na Convenção de 1951, e a forma de perseguição é o dano ambiental; assim, trata-se de um refugiado. Nesse sentido, deve-se estabelecer o fundado temor de perseguição. ${ }^{11}$

Por mais que o objetivo das autoras seja o de resguardar a vida e a dignidade de milhares de pessoas, a interpretação extensiva da Convenção sobre Refugiados é inviável, pois os danos decorrentes do dano ambiental não podem ser individualizados.

Outro impedimento ocorre em virtude do motivo em que se sustenta a concessão do refúgio, ou seja, o indivíduo que solicita o status de refugiado é perseguido por motivo de raça, religião, nacionalidade, grupo social ou opinião política, o que não é possível ocorrer no presente caso.

${ }^{11}$ Jubilut, Liliana Lyra; Apolinário, Silvia Menicucci, O. S. A necessidade de proteção internacional no âmbito da migração. Revista Direito GV, São Paulo 6(1), p. 275-294, p. 288, jan./ jun 2010. Disponível em: <http://www.scielo.br/pdf/rdgv/v6n1/13.pdf>. 
Tendo em vista as incompatibilidades no enquadramento do "refugiado ambiental” pela Convenção de 1951, alternativas devem ser repensadas e analisadas. Uma delas é o papel das Convenções Regionais de Direitos Humanos, que possuem obrigação subsidiária em tutelar tais indivíduos. Um grande passo já foi dado pela Declaração de Cartagena e a Convenção da Unidade Africana, citadas anteriormente. $O$ fato de abranger o conceito de refugiado e utilizar termos que possibilitem a interpretação, favorece no auxílio de garantias aos "refugiados ambientais”, como, por exemplo, o termo utilizado na Declaração de Cartagena “[...] ou outras circunstâncias que tenham perturbado gravemente a ordem pública”, podendo enquadrar como agravamento da ordem pública o resultado de um grande número de migrantes em decorrência de danos ambientais ${ }^{12}$ (Trindade, 2006).

Vale destacar o papel desempenhado pelo governo das Ilhas Maldivas que (constando que, em virtude do aumento do nível do mar, pode desaparecer) com o apoio de vários países, ONGs, Organizações Internacionais e, após uma consulta com os seus Ministérios e delegações das Nações Unidas, lançou, no ano de 2006, como proposta a toda comunidade internacional, a adoção de um novo protocolo relativo ao Estatuto dos Refugiados de 1951, tendo como objetivo central o enquadramento do status de refugiados ambientais. ${ }^{13}$ (Ramos, 2011).

Quem também emerge nesse cenário com importante papel são as Organizações não Governamentais - ONGs. Atualmente foram criadas várias ONGs, cujo centro das atividades é a questão dos "refugiados

\footnotetext{
${ }^{12}$ Alto Comissariado das Nações Unidas para os Refugiados. Acnur. Declaração de Cartagena de 1994: Terceira Conclusão. Disponível em: <http://www.acnur.org/t3/portugues/recursos/documentos/?tx_danpdocumentdirs_pi2\%5Bmode\%5D=1\&tx_danpdocumentdirs_ pi2\%5Bfclick $\% 5 \mathrm{D}=, 145 \& \mathrm{tx}$ _danpdocumentdirs_pi2\%5Bfolder\%5D=146\&tx_danpdocumentdirs_pi2\%5Bsort $\% 5 \mathrm{D}=$ doctitle,sorting,uid\&tx_danpdocumentdirs_pi2\%5Bpointer\% $5 \mathrm{D}=0$.>. Acesso em: 6 jan. 2014.

${ }^{13}$ Para maiores informações, acessar: <http://www.environment.gov.mv/v1/>.
} 
ambientais”. Podemos destacar o papel da Living Space for Enviromental Refugees (Liser), fundada na Holanda, que é “[...] uma organização orientada para o reconhecimento e distinção dos refugiados ambientais” ${ }^{14} \mathrm{e}$ possui nível de atuação global, bem como a marcha mundial SOS clima Terra, que possui preocupação acerca dos problemas ambientais. ${ }^{15}$

Uma solução temporária para o problema é uma alternativa válida diante das atuais dificuldades. As soluções temporárias podem vir a se tornar permanentes e podem facilitar e demonstrar pontos que devem ser melhorados na busca por uma solução permanente.

Os debates e fóruns promovidos no âmbito das Nações Unidas, bem como seus órgãos que estudam direta ou indiretamente o problema das alterações climáticas, fazem nascer maior consciência na comunidade internacional para enfrentar o problema.

Sem dúvidas, a maior lacuna que hoje enfrentamos é não abordar as responsabilidades específicas dos Estados-Membros e outros autores responsáveis que não respondem adequadamente para diminuir, amenizar ou até mesmo preocupar-se com os problemas diretamente como corresponsáveis.

\section{CONSIDERAÇÕES FINAIS}

Os "refugiados ambientais" enfrentam hoje inúmeras dificuldades na busca pela proteção jurídica internacional. Podem ser citadas como causas principais a ausência de previsão normativa, a não aceitação do Acnur como status de refugiado, a falta de consenso sobre o conceito em razão da multiplicidade de fatores, bem como o principal desafio, que advêm da obrigação de migrar em decorrência dos danos ambientais.

\footnotetext{
${ }^{14}$ Ver mais em: <http://www.liser.eu/>.

${ }^{15}$ Maiores informações: <https://www.youtube.com/watch?v=29IEQdMmevM>.
} 
A atual complexidade global desafia a comunidade internacional e todos os atores que a compõe. O número de conflitos, principalmente pela religião, e o aumento de grupos extremistas, deixam como rastros a destruição, o aumento do ódio e o fanatismo.

Diante de todos os conflitos, surge no âmbito internacional novos debates na tentativa de algum progresso da atual realidade ou de solução. Por mais que não exista um conceito definido sobre quem são os "refugiados ambientais”, é irrefutável que atitudes devem ser analisadas na tentativa de resguardar os direitos humanos dos indivíduos que se encontram em tais situações. Direitos mínimos que todos possuem e que, na maioria das vezes, as violações são gritantes.

O conceito de "refugiado ambiental" deve enquadrar tanto os indivíduos que deixaram o seu local de origem deslocando-se dentro da fronteira de seu país ou internacionalmente. Deve-se ter como elemento-chave que a migração ocorre em decorrência da alteração climática, sendo este típico, atípico, influenciado ou não pelo homem.

A principal lacuna que deve ser preenchida é a responsabilização dos Estados e outros órgãos que, direta ou indiretamente, colaboram para que os problemas ambientais se agravem, e que, paralelamente, não possuem nenhuma obrigação perante a comunidade internacional.

A solução do problema está em sua raiz, mas nenhum Estado quer se comprometer e verdadeiramente solucionar o problema. Destaca-se, assim, o trabalho dos demais atores internacionais, principalmente as ONGs, que podem buscar amenizar o sofrimento e criar possibilidades de mudança.

\section{REFERÊNCIAS}

ALTO COMISSARIADO DAS NAÇÕES UNIDAS PARA OS REFUGIADOS. Acnur. Agência da ONU para refugiados. Disponível em: $<$ http://www.acnur. org/t3/portugues/o-acnur/>. Acesso em: 15 jan. 2014a. 
Acnur. Declaração de São José para refugiados e pessoas deslocadas. S. José, 5-7 de dez. 1994. Disponível em: <http://www.acnur.org/t3/portugues/ recursos/documentos/>. Acesso em: 6 jan. 2014b.

Acnur. Declaração de Cartagena de 1994: Terceira Conclusão. Disponível em: <http://www.acnur.org/t3/portugues/recursos/documentos/?tx_ danpdocumentdirs_pi2\%5Bmode $\% 5 \mathrm{D}=1 \&$ tx_danpdocumentdirs_pi2\% $5 \mathrm{Bfcli}-$ ck\%5D=,145\&tx_danpdocumentdirs_pi2\%5Bfolder\%5D=146\&tx_danpdocumentdirs_pi2\%5Bsort $\% 5 \mathrm{D}=$ doctitle,sorting,uid\&tx_danpdocumentdirs_pi2\%5Bpointer\%5D=0 . Acesso em: 6 jan. 2014 .

BLACK, Richard. Environmental refugees: myth or reality? University of Sussex Falmer, Brighton Bn1 9sj United Kingdom, Reino Unido, v. 1, n. 34, p. 1-20, mar. 2001. Disponível em: <http://www.unhcr.org/3ae6a0d00.html>. Acesso em: 6 jan. 2014.

BRASIL. Convenção relativa ao estatuto dos refugiados. Promulgada pelo Decreto n. 50.215 de 28 de janeiro de 1961. Disponível em: <http://www2. mre.gov.br/dai/refugiados.htm>. Acesso em: 12 dez. 2013.

. Convenção-Quadro das Nações Unidas sobre mudança do clima. Adotada em 9 de maio de 1992. Promulgada pelo Decreto no 2.652, de $1^{\circ} \mathrm{de}$ julho de 1998. Disponível em: <http://www.mct.gov.br/index.php/content/ view/20245.html>. Acesso em: 12 dez. 2013.

CAMPOS, André. Refugiados ambientais: deslocamentos humanos provocados por alterações no meio ambiente são um problema crescente no mundo - e afetam também o Brasil. Situação é tão preocupante que a ONU debate criação de leis internacionais sobre o tema. Repórter Brasil. Disponível em: $<\mathrm{http}: / /$ reporterbrasil.org.br/2006/12/refugiados-ambientais/>. Acesso em: 6 jan. 2014.

JUBILUT, Liliana Lyra; APOLINÁRIO, Silvia Menicucci, O. S. A necessidade de proteção internacional no âmbito da migração. Revista Direito Gv., São Paulo, p. 275-294, jan./jun. 2010. Disponível em: <http://www.scielo.br/pdf/ rdgv/v6n1/13.pdf $>$. Acesso em: 17 dez. 2013. 
LAM, Andrew. The Rising Tide of Environmental Refugees: No longer a "hidden crisis," millions are on the move due to ecological collapse. 2012. Disponivel em: <http://thetyee.ca/Opinion/2012/08/20/Environmental-Refugees/>. Acesso em: 28 dez. 2013.

LIVING SPACE FOR ENVIRONMENTAL REFUGEES. Liser Refugiados ambientais. Disponível em: <http://www.liser.eu/>. Acesso em: 12 dez. 2013. MCADAM, Jane. Legal and Protection Policy Research Series: Climate Change Displacement and International Law: Complementary Protection Standard. 2011. Division of International Protection. United Nations High Commissioner for Refugees. Disponível em: <http://www.unhcr.org/cgi-bin/texis/ $\mathrm{vtx} /$ home/opendocPDFViewer.html?docid=4dff16e99\&query=environmental refugees>. Acesso em: 6 jan. 2014.

MYERS, Norman; KENT, Jennifer. Enviromental Exodus: An Emergent Crisisin the Global Arena. Washington: Project Of The Climate Institute, 1995. 246 p. Disponivel em: <http://www.climate.org/PDF/Environmental Exodus. pdf $>$. Acesso em: 5 dez. 2013.

ORGANIZAÇÃO DAS NAÇÕES UNIDAS. The Anatomy of A Silent Crisis: Human Impact Report Climate Change. Global Humanitarian Forun, Geneva.. Disponível em: <http://www.eird.org/publicaciones/humanimpactreport. pdf $>$. Acesso em: 14 nov. 2013a.

. Declaração do Rio sobre meio ambiente e desenvolvimento. Disponível em: <http://www.mma.gov.br/sitio/index.php?ido=conteudo.monta\&idEstr utura=18\&idConteudo=576 $>$. Acesso em: $17 \mathrm{dez} .2013 \mathrm{~b}$.

Conselho de Segurança, 5663rd Meeting, 17 abr. 2007. Acesso em: 15 jan. 2014.

ORGANIZAÇÃO DA UNIDADE AFRICANA (OUA). Convenção da Organização de Unidade Africana (OUA) que rege aspectos especificos dos problemas de refugiados na África. Disponível em: <http://www.acnur.org/t3/portugues/ recursos/documentos>. Acesso em: 6 jan. 2013. 
PINTO, Anne Fernanda Rocha da Silva. Refugiados ambientais. In: Âmbito Jurídico, Rio Grande, XII, n. 71, dez. 2009. Disponível em: <http://www. ambito-juridico.com.br/site/index.php?n_link=revista_artigos_leitura\&artigo_id=6845>. Acesso em: jan. 2014.

RAMOS, Érika Pires. Refugiados ambientais: em busca de reconhecimento pelo direito internacional. 150 f. Tese (Doutorado) - Universidade de São Paulo, Curso de Direito, Departamento de Centro de Ciências Jurídicas, São Paulo, 2011. Disponível em: <http://www.acnur.org/t3/fileadmin/Documentos/portugues/eventos/Refugiados_Ambientais.pdf?view=1>. Acesso em: 3 jan. 2014.

RAKOVA, Ursula. How-to Guide for Environmental Refugees. 2009. Our World: Brought to you by UN University. Disponível em: <http://ourworld.unu.edu/ en/how-to-guide-for-environmental-refugees $>$. Acesso em: 6 jan. 2014.

REPUBLIC OF MALDIVES (Ministry of Environment, Energy and Water). Disponível em: <http://www.environment.gov.mv/v1/>. Acesso em: $20 \mathrm{dez}$. 2013.

TERMINSKI, Bogumil. Environmentally-Induced Displacement. Theoretical Frameworks and Current Challenges. Geneva, 2011. Disponivel em: $<\mathrm{http}: / /$ www.cedem.ulg.ac.be/wp-content/uploads/2012/09/Environmentally-Induced-Displacement-Terminski-1.pdf>. Acesso em: 17 nov. 2013.

TRINDADE, Antônio Augusto Cançado. Direitos humanos e meio ambiente: paralelos dos sistemas de proteção internacional. Porto Alegre: Sergio Antonio Fabris, 2006.

ZARPELON, Janiffer Tammy Gusso; ALENCASTRO, Mário Sérgio Cunha; MARCHESINI, Otavio Ernesto. Refugiados ambientais: um desafio global. Ciência e Cultura, Curitiba, n. 44, p. 163-182, 2010. Disponível em: <http:// www.utp.br/tuiuticienciaecultura/ciclo_4/tcc_44_FACSA/pdfs_44/art7_refugiados.pdf $>$. Acesso em: 26 ago. 2015.

Recebido em: 22/5/2014

Aceito em: 23/12/2014 